\title{
Twenty Years of Financial and Bank Reforms in the Czech Republic - Bird View
}

\section{Dear readers,}

who was afraid that conference "Twenty years of financial and bank reforms in the Czech Republic" which was organized on November 11, 2009 by Faculty of Finance and Accounting of the University of Economics, Prague in collaboration with Czech National Bank, will be mainly nostalgic and memory optimism hindsight to years of transformation, was pleasantly surprised. Of course, it does not mean the data and events of important transformation steps have not been mentioned. They have been, however, used by most of presenters to topical and sometimes also critical considerations about topics highly substantial for the future.

I believe that content of the conference, which was by its spirit (and certainly in favour its quality) more work than celebration oriented, will be the subject of professional analyses of bank and financial experts; there is a lot of areas worth to do it. As I do not feel to be specialist to those problems, let me come to think of conference benefits in more general circumstances; they can be interesting for all of us who shares over activities connected with solution of our faculty research project "Financial and accounting theory development and its application from the interdisciplinary view-point".

The fact we live professional part of our life in quite exceptional time and territory has been - in my view - principle general conference motto. No only time connections which enable us to analyse individual attributes of transformation from pre-November initials to developed democratic society but also comparison with countries experiencing analogical development and with those which serves as standard for us in concrete parameters create huge potential for our objective, neutral research.

It has been sympathetic in this regard that most of experts who has been influenced progress of the last twenty years (including $\mathrm{Mr}$. President) were very frank in their presentations and correct in the sense of "we have been to act differently in some decisions", "we have 
undervalued incidence of this factor" or ,we have been mistaken as we have come from a pre-condition which have not been confirmed". Recent reflection of the globe in the image how is created by politics and presented in a simplified way by medias create an impression that it is not acceptable to admit a mistake. This rule cannot be accepted for scientific investigations and it is good message that it has not been applied by the conference speakers.

Objectivity and neutrality of our research activities is also connected with non-written custom "not to mark" or "not to label" phenomena on the basis of their far historical or social connections. „Phenomena are not, or bad", stated Vladimír Dlouhý in response to reservation his paper does not state quite definitely whether he support quick Euro implementation, or not, and he continued: "they (phenomena) are such they are" - and this is the reason why we must investigate them in mutual inter-relations of their strengths, weaknesses, opportunities and threats".

Consequently, although we must be transparent in our opinions and final statements regarding differentiation from an alternative opinion, it is not contradict to our statement if we disclose also its risks and limitations and it is not our loss to admit that an alternative opinion has its strengths.

We have great advantage in our investigations - we are not tight with already realised decisions: we are not authorised - unlike executives - to argue together with Miroslav Kalousek "it is waste of time to discuss whether to accept Euro or not because we have already committed ourselves to accept it in admittance treaty"; on the other hand, it belongs to our rights and (sometimes not very pleasant) obligations to defend our opinion regardless the fact it is not "on the program", conform or formally winning.

One of very popular labels is given by disparagement of "practitioners" to conceptual considerations. There was no miracle in this regard that also during conference (rightful) note has sounded from Richard Salzman to Kamil Janáček opinion whether transformation of banks could be managed by a more efficient way. However, the way of the note introduction coming from consideration "this is the way how theorists but not practitioners think" has not been quite correct regardless nobleness of its reciting. Nevertheless, reaction of professor Janáček was very convictive: it was quite apparent that the whole problem perceived in much more stronger integration of theory and practise than 
how it had derived allegedly from his timely limited presentation. No surprise: despite "accusation" he is not only expert with huge scientific potential but also personality with close relation to practise which he has always been taking as principle corrective of his general scientific outcomes.

In my opinion, this non-important episode could be also an inspiration for us who formulates general conclusions in the frame of our scientific ambitions. In rational conditions any contradiction between theory and practise cannot exist; it is not sense of our research activities to construct models based on pre-conditions which will never come into existence. Our main target is - as well as in other areas of the human efforts - to find a „customer" - user whom we are able to enrich with regard his/her practical information needs. Consequently, it is inevitable for us and for our research project (regardless its orientation to "theory" in its title) to come from the practical needs primarily. Of course, it requires - besides others - to know practise and its problems. Just only in the case our conceptual outcome will bring benefit in the test of practical application it also fulfils its principle sense.

Nevertheless, not only synergy of our theoretical and practical knowledge is sufficient for our scientific aims reaching. Although our scientific investigations do not necessarily meet moral and ethical aspects allegedly, there is no doubt that only such solutions win in strategic run which are not only practically beneficial and theoretically justifiable but also solutions which are correct from the moral and ethical viewpoints. Probably in Martin Mandel presentation has sounded this aspect by the strongest way. He has elaborated topic highly specific in his presentation - preconditions of exchange rate will retain a stabled element of our economy; nevertheless, in the survey of these preconditions he has also stressed more general values of all our activities including scientific ones: in his view, to principle pillars of the exchange policy has belonged (and it should also belong in the future) fixation of rules, long-term consistency, effort to fulfil declared aims, accompanied by continual process of corrections between prognoses and reality, transparency, understand ability and fair attitude in disclosure and analyses of results.

There is no dispute that not only professional competence but also above stated principles has contributed substantially to the exchange rate of Czech crown development; it is perceived recently as non-disputable positive feature of our transformation. It is certainly accompanied by 
many questions and problems; there is no doubt, however, in main parameters it is oriented by correct direction. I am convinced these principles create guarantee for the success of our scientific activities as well - and not only of them.

prof. Ing. Bohumil Král, CSc.

member of Editorial board of

European Financial and Accounting

Journal

and head of

Department of Managerial

Accounting 